\title{
Brugaletta, Federico (2019). Tierra Nueva (1969-1985). Protestantismo de izquierda, edición y educación en la historia reciente de América Latina
}

\author{
Dahiana Barrales Palacio \\ dahiabarrales@gmail.com \\ Universidad Nacional de La Plata, Argentina
}

Cita sugerida: Barrales Palacio, D. (2021). [Revisión de Tesis Tierra

Nueva (1969-1985). Protestantismo de izquierda, edición y educación en la historia reciente de América Latina]. Aletheia, 11(22), e098. https://doi.org/10.24215/18533701e098

Defensa de Tesis: 8 de marzo de 2019

Directora: Dra. Silvia Finocchio

Codirectora: Prof. Ana Barletta

Tierra Nueva (1969-1985). Protestantismo de izquierda, edición y educación en la historia reciente de América Latina es el nombre con el cual Federico Brugaletta (2019) tituló a su tesis de Maestría en Historia y Memoria. Allí, el autor propone explicar y comprender la experiencia de la editorial Tierra Nueva como un proyecto político, intelectual y educativo del protestantismo de izquierda en la historia reciente de América Latina. Aquí, Brugaletta hace ciertos ejercicios analíticos que resultan interesantes: el primero consiste en que, si bien ya en el título delimita el marco temporal a los años en los cuales el sello editorial estuvo en funcionamiento (1969-1985), en su tesis se puede ver que, por momentos, amplía esta escala y se percibe claramente la necesidad de hacerlo; por otro lado, combina distintas escalas espaciales, pone énfasis en Montevideo y en Buenos Aires, más aclara que su trabajo incluye otras territorialidades a nivel de Latinoamérica y Europa.

Esta doble combinación de dimensiones espaciales y temporales seguramente esté dada por múltiples factores, algunos de los cuales los hace explícitos y otros no. El primero de ellos refiere a la propia elección temática, a los objetivos que se propuso cumplir en su investigación y a cómo entendió a Tierra Nueva. La combinación de esas dimensiones le permite evidenciar y abordar la complejidad que supone considerar a la editorial como parte de un «circuito de comunicación»y, al mismo tiempo, tratarla como un proyecto político, intelectual y educativo. El segundo, es el haber elegido que la trayectoria intelectual del editor de Tierra Nueva tuviera un lugar significativo en esa propuesta de explicar y comprender la experiencia de 
la editorial. Este último elemento es uno de los mayores aciertos de la tesis de Brugaletta. Por un lado, constituye un aporte metodológico para quienes proponemos en nuestras tesis trabajar con trayectorias, ya sean intelectuales, políticas, militantes y/o religiosas y, por otro lado, pone de manifiesto las imbricadas relaciones entre historia y memoria. El tercer factor es el entendimiento - por parte del autor- de que, al abordar los vínculos entre cristianismos e izquierdas, tenía el desafío de situar este proyecto político, intelectual y educativo en procesos de larga y mediana duración que, en muchas ocasiones, se insertan en (o dialogan con) corrientes teológicas que quizás no sean del todo conocidas por la academia argentina y uruguaya -sobre todo en esta última- producto de la cultura laicista en la que se inscribe. Finalmente, necesita esta combinación de escalas para explicar la coyuntura política de la historia reciente de Argentina y Uruguay, así como también para mostrar la gestación y lo «novedoso» de este protestantismo en el que pretende situar a Tierra Nueva.

La tesis se estructura en tres capítulos. En el primer capítulo, Brugaletta caracteriza el contexto del surgimiento de la editorial Tierra Nueva. Señala como importante destacar que esta editorial surge de la intersección de dos vectores: uno que refiere al agrupamiento de Iglesia y Sociedad en América Latina (ISAL) y el otro a la figura de Julio Barreiro en tanto editor. ISAL nació en el año 1961 vinculado al Consejo Mundial de Iglesias (CMI). El CMI, fundado en el año 1948, estaba integrado por una red transnacional de iglesias protestantes con sede en Ginebra. Desde su fundación, la sede de ISAL estuvo en Montevideo y contó con el apoyo de la Iglesia metodista uruguaya. El autor señala que esta asociación "particular con el metodismo uruguayo no fue casual ya que poseía una importante tradición de vínculos ecuménicos y activismo social” (Brugaletta, 2019, p. 29). Si bien Brugaletta acude a nota al pie para contextualizar tal afirmación, lo hace en referencia al metodismo a nivel europeo y de Latinoamérica; la interrogante que surge es conocer cuál es esa tradición de vínculos ecuménicos y activismo social en la que se inscribe la Iglesia metodista uruguaya.

El autor define a ISAL "como una minoría intensa dentro del protestantismo latinoamericano que concibió una forma revolucionaria de ser cristianos al tiempo que imaginó una vía cristiana para hacer la revolución" (p. 25). Identifica a aquellos teólogos vinculados a ISAL que fueron promotores o productores de la teología de la liberación latinoamericana en clave protestante, haciendo énfasis en la teología neo-ortodoxa alemana. Un elemento de interés que se podría abrir a partir de este apartado es sobre el diálogo entre católicos y protestantes, sea por espacios compartidos o por corrientes y preocupaciones teológicas comunes.

Brugaletta destaca que en la teología retomada y promovida por ISAL se dio un fortuito diálogo con el pensamiento marxista, en tanto se entendió este como herramienta que permitía un análisis de la realidad que se proponían transformar. Este diálogo con el pensamiento marxista se vio reflejado en la principal publicación periódica de ISAL, la revista Cristianismo y Sociedad. Para el autor, los protestantes de ISAL lograron -a través de esta publicación- desarrollar prácticas propias del mundo secular.

Otro de los apartados dentro de este capítulo es el que refiere a la trayectoria religiosa e intelectual de Julio Barreiro. La figura de Barreiro le permite a Brugaletta mostrar los principales espacios de socialización cristiana transitados por este editor, pero compartidos con otros cristianos que fueron parte de ISAL, así como poner en relación al metodismo en Uruguay con las redes ecuménicas transnacionales.

Finalizando el primer capítulo, Brugaletta se detiene en el elemento educativo del proyecto político, intelectual y educativo señalado al principio. Facilita las primeras pistas de la vinculación de ISAL con Paulo Freire; menciona una serie de capacitaciones y la formulación de un proyecto pedagógico con asesoría de Paulo Freire, que se desarrolló en una "barriada" de Montevideo. Una línea de investigación interesante para profundizar sobre este tema sería la relación de este proyecto con el desarrollado por los jóvenes metodistas de la Iglesia metodista del Barrio Malvín, quienes también manifiestan en sus testimonios la necesidad de desarrollar proyectos de concientización crítica política en los cantegriles.

En el segundo capítulo se caracteriza el proyecto Tierra Nueva. Atiende a los procesos políticos de la historia reciente del Uruguay y a las posiciones de Julio Barreiro con respecto a tal coyuntura. El autor sitúa 
a Tierra Nueva en el contexto del autoritarismo pachequista, la radicalización y las discusiones sobre las vías de transformación social en diversos movimientos y partidos políticos. Presenta algunas de las opiniones públicas de Barreiro, quien -entre otras cosas- creía que era necesario crear un "frente de masas" en la lucha revolucionaria y un proyecto de sociedad de tipo socialista.

Además de los aspectos analíticos ya destacados, también es notorio su enfoque metodológico, el trabajo que hizo con el archivo familiar/personal de Barreiro y el relevamiento testimonial, pero fundamentalmente la cantidad de "trazos" que pudo realizar a partir de la lectura atenta de las correspondencias entre Barreiro y otras personas del ámbito editorial. Este trabajo le permite a Brugaletta precisar sobre las intenciones que tenía el editor sobre Tierra Nueva, a qué mercado quería acceder y qué catálogos configuraría. El autor subraya que el proyecto editorial se presentaba con un explícito compromiso político asociado a las iniciativas políticas de izquierda. Dentro de la producción editorial se destaca a Paulo Freire como uno de los autores centrales con el que contó el catálogo de Tierra Nueva.

En el último capítulo se caracteriza la segunda y última etapa de la editorial, desarrollada ya en Buenos Aires entre los años 1974 y 1985. De forma cronológica, Brugaletta da cuenta de la vida de Barreiro y la reconfiguración del catálogo de Tierra Nueva en el periodo antes señalado. La descripción de los acontecimientos que llevaron a Barreiro a exiliarse se logra de una forma muy significativa, porque otorga un lugar especial a los testimonios y a la correspondencia familiar; esto introduce una dimensión que, si bien se sigue centrando en la figura de Barreiro en tanto es él el editor de la revista, nos permite situar a una familia que vive la experiencia represiva primero en Uruguay y luego en Argentina.

Un elemento interesante de este capítulo es cómo Barreiro irá comprendiendo el escenario en el que estaba inserto y las prácticas editoriales que debía desarrollar como editor para continuar publicando, pero teniendo en cuenta que estaba en un escenario que restringía o censuraba a las editoriales de izquierdas. Por momentos, la lectura otorga cierta sensación de soledad en términos de que las decisiones parecen recaer en la figura de Barreiro; me pregunto si esto se debe a la opción del autor de centrarse en el editor o es que, efectivamente, para esta etapa Barreiro se encontraba en tal situación. El cuarto apartado refiere a la reconfiguración del catálogo de Tierra Nueva en Buenos Aires; es interesante, prestando atención a los títulos, cómo en estos se reflejan los avatares que la editorial debió sortear para seguir publicando, así como también los cambios en los temas, discusiones y el "horizontes de expectativas" que estaba cambiando. El último apartado traza el retorno de Barreiro a Uruguay y da pistas sobre las múltiples causas del cierre de Tierra Nueva.

Esta tesis es un gran aporte a varias investigaciones que se vienen desarrollando en Uruguay vinculadas a la temática. Su tesis presenta una contribución innegable al campo de los estudios sobre los vínculos entre religión y política, así como entre cristianismo e izquierdas en los años sesenta y setenta. Asimismo, Brugaletta posee la riqueza de agregarle el elemento educativo, el cual, en vínculo con política y religión, tensiona la cultura laicista uruguaya. 